
Major Evolutionary Transitions

\title{
Implications for Psychological Science
}

\author{
David Sloan Wilson, ${ }^{1}$ Mark Van Vugt, ${ }^{2}$ and Rick O'Gorman ${ }^{3}$ \\ ${ }^{1}$ Departments of Biology and Anthropology, Binghamton University; ${ }^{2}$ University of Kent at Canterbury, Canterbury, \\ United Kingdom; and ${ }^{3}$ Sheffield Hallam University, Sheffeld, United Kingdom
}

\begin{abstract}
The concept of a group as comparable to a single organism has had a long and turbulent history. Currently methodological individualism dominates in many areas of psychology and evolution, but natural selection is now known to operate at multiple levels of the biological hierarchy. When between-group selection dominates within-group selection, a major evolutionary transition occurs and the group becomes a new, higher-level organism. It is likely that human evolution represents a major transition, and this has wide-ranging implications for the psychological study of group behavior, cognition, and culture.
\end{abstract}

KEYWORDS-group selection; human evolution; multilevel selection theory; group psychology; culture

The concept of a social group as a single organism has a long history in scientific and intellectual thought. According to Daniel Wegner (1986, p. 185),

Social commentators once found it very useful to analyze the behavior of groups by the same expedient used in analyzing the behavior of individuals. The group, like the person, was assumed to be sentient, to have a form of mental activity that guides action. Rousseau and Hegel were the early architects of this form of analysis, and it became so widely used in the 19th and early 20th centuries that almost every early social theorist we now recognize as a contributor to modern social psychology held a similar view.

Nevertheless, during the second half of the 20th century this view of society was eclipsed by a more reductionistic and individualistic view. Donald Campbell (1994, p. 23) wrote: "Methodological individualism dominates our neighboring fields of

Address correspondence to David Sloan Wilson, Department of Biology, Binghamton University, Binghamton, New York, 13902-6000; e-mail: dwilson@binghamton.edu. economics, much of sociology, and all of psychology's excursions into organizational theory. This is the dogma that all human social group processes are to be explained by laws of individual behavior."

Developments in evolutionary biology seemed to affirm the individualistic turn in psychology. Darwin wrote about how groups can potentially, but not invariably, evolve into adaptive units (Richards, 1987). Unfortunately, many of his followers assumed that natural selection operates on individuals, groups, species, and ecosystems, as though there were no need to distinguish among levels of the biological hierarchy. These ideas were criticized in the 1960s, and a two-part consensus emerged (Williams 1966). First, higher-level entities such as social groups can evolve into adaptive units, but only by a process of higher-level selection. For example, an altruistic behavior that benefits others at the expense of the self is selectively disadvantageous within groups. However, if there are many groups in the total population that vary in the frequency of altruists, the most altruistic groups will differentially contribute to the total gene pool. Between-group selection favors altruism and can counteract within-group selection if it is sufficiently strong, causing the altruistic trait to evolve in the total population. This way of conceptualizing evolution is called multilevel selection (MLS) theory (Sober \& Wilson, 1998).

Even though group-level adaptations can evolve in theory, the second part of the consensus concluded that they seldom do so in the real world, because group-level selection is almost invariably weaker than individual-level selection. This conclusion was so widely accepted that group selection became a pariah concept, taught primarily as an example of how not to think. The theoretical justification for individualism in psychology seemed secure.

Nevertheless, much has happened in evolutionary biology during the last half century (Wilson \& Wilson, 2007). The first part of the 1960s consensus remains valid: Adaptations at any given level of the biological hierarchy require a process of

\begin{tabular}{|c|c|}
\hline C D I R & 538 \\
\hline Journal Name & Manuscript No. \\
\hline
\end{tabular}


natural selection at that level and tend to be undermined by lower levels of selection. The second part of the consensus has proven to be erroneous: Higher-level selection can be a significant evolutionary force, one that sometimes even dominates lower-level selection, causing the higher-level unit to become an organism in every sense of the word. Ironically, given group selection's previous pariah status, it is now the concept of groups as organisms that stands on a firm scientific foundation. Moreover, it is likely that human evolution represents such an evolutionary transition, and this has profound implications for psychology and all other human-related subjects.

\section{ORGANISMS AS GROUPS}

When between-group selection dominates within-group selection, a major evolutionary transition occurs. The social group becomes a higher-level organism and the members of the group acquire an organ-like status. This idea was first proposed to explain the evolution of eukaryotic (nucleated) cells, not by small mutational steps from prokaryotic (bacterial) cells, but as highly integrated symbiotic associations of bacteria. The idea was then generalized to include other major transitions, including the first cells, multicellular organisms, social insect colonies, and even the origin of life as groups of cooperating molecular interactions (Maynard Smith \& Szathmary, 1995).

Major transitions have a number of hallmarks: First, they are rare events in the history of life. It is not easy for between-group selection to dominate within-group selection. All species of eusocial insects (e.g., ants, bees, wasps, and termites), for example, are thought to be derived from only 15 original transitions from solitary insect species. Second, major transitions have momentous consequences once they occur. Individuals and uncoordinated groups are no match for the new superorganisms, which quickly become ecologically dominant. Third, the transition is never complete. Even multicellular organisms, which might seem like paradigms of internal harmony, contain a disturbing number of genes that spread at the expense of other genes in the same organism, rather than for the good of the organism (cf. intragenomic conflict).

\section{THE HUMAN MAJOR TRANSITION: IMPLICATIONS FOR PSYCHOLOGICAL SCIENCE}

It is likely that early human evolution represented a major transition, turning our ancestral groups into the primate equivalent of bodies or beehives. All of the hallmarks are present: It was a rare event, occurring only once among primates. The consequences were momentous; mere individuals and less coordinated groups were no match for the new superorganisms, which spread over the globe, eliminating other hominid species and thousands of other species along the way. The transition is not complete; individuals still succeed at the expense of other individuals within the same group. The scope for within-group selection is merely suppressed, turning between-group selection into a relatively stronger evolutionary force.

This multilevel view of human evolution, with a strong (but not exclusive) emphasis on group selection, has foundational implications for psychological science. These implications are not entirely new, however, because psychology has its own tradition of group-level thinking, as we stressed at the beginning of this article. Instead, MLS theory can provide a new foundation for longstanding themes in psychological research, a sample of which will now be described.

Psychology of Altruism, Cooperation, and Morality A major transition requires mechanisms that suppress conflict among individuals within groups, enabling groups to become the primary unit of selection. Multicellular organisms and social insect colonies could not function as adaptive units without internal social-control mechanisms (Maynard Smith \& Szathmary, 1995). In humans, the traits associated with moral systems appear to perform the same function. Small-scale human society (the only scale during most of human evolution) is remarkable for the degree of social control that members can exert over each other. In human societies, unlike those of most primate species, no single individual can dominate the others in their group. Behaviors that benefit some members at the expense of others are easily detected, communicated, and punished at relatively low cost to the punishers. These social-control mechanisms establish a kind of guarded egalitarianism that Boehm (1999) terms a "moral community," and which characterizes virtually all known hunter-gatherer societies.

The experimental games literature shows the importance of social control for the maintenance of cooperation in human groups. When given an opportunity to cooperate, most people are moderately generous until they perceive that they are being exploited by more selfish ingroup members, after which they withhold their own cooperation (De Cremer \& Van Vugt, 1999). At least some members are highly motivated to punish selfish behavior, however, even at their own private expense, resulting in high levels of cooperation (Fehr \& Gächter, 2002). Grouplevel selection thinking forces researchers to reconsider the notion of Homo economicus and replace it with a more complex picture, one that includes human preferences for altruism, benevolence, retaliation, contrition, fairness, forgiveness, and so on.

These and other traits associated with human morality and cooperation are based on neurobiological mechanisms that are primarily automatic and emotive (e.g., social emotions like anger and guilt) rather than conscious and deliberative. Moral intuition comes first and is only partially overridden by moral reasoning. Haidt (2007) shows that early theorizing about morality, dating back to first psychologists like Wilhelm Wundt and William James, can be placed on a contemporary foundation based on MLS theory. 


\section{Group Cognition and Performance}

Cooperation evolves in the context of cognitive activities such as perception, attention, memory, and decision making, in addition to physical activities such as hunting, gathering, warfare, and childcare. The social insects are well known to cooperate on cognitive tasks, to the point where they can truly be said to possess a group mind (Seeley, 1995). Just as individual cognition is based on interactions between neurons, with any particular neuron playing a limited role, group cognition is based on social interactions, with any particular individual playing a limited role.

MLS theory can organize the study of group-level cognition in humans, providing a framework for interpreting the existing psychological literature and suggesting directions for future research. For example, cooperation is required only for tasks that exceed the capacity of individuals, yet task complexity has seldom been manipulated as an independent variable in groupcognition research. Using a task based on the game of 20 questions, Wilson, Timmel, \& Miller (2004) showed that groups perform better than individuals do and that the performance gap increases with the difficulty of the word being guessed. Group performance is uncorrelated with the performance of individual members playing alone, and playing in a group does not subsequently improve individual performance. In other words, the advantages of playing as a group require being in a group. The performance advantage of groups could be demonstrated even when the task was presented in the format of a brainstorming experiment, where advantages of real groups compared to nominal groups (i.e., merged results of individuals playing alone) have been notoriously difficult to demonstrate (Mullen, Johnson, \& Salas, 1991).

Although cognitive cooperation has received some attention in psychological research (i.e., transactive memory; Wegner, 1986), MLS theory suggests that it deserves to occupy center stage in research on group cognition and performance.

\section{Leadership and Group Decision Making}

Leadership has long occupied the attention of psychologists, with 7,500 studies cited in the most recent Handbook of Leadership. Yet, researchers frequently comment that the field is poorly integrated. MLS theory can provide a unifying theoretical framework for interpreting the existing literature and suggesting new research directions (Van Vugt, 2006). Two major hypotheses about leadership correspond directly to selection at the individual and group levels. The first is that leadership is a byproduct of social dominance within the group. Individuals compete for power and the winners get to make the decisions, forcing the losers to submit to them. The second is that leadership is part of an organizational structure that functions well at the group level. Coordinating action and making collective decisions for the good of the group often require leader-follower relationships.
Making sense of human leadership requires both hypotheses. Individual selection models suggest there are always at least some individuals who wish to acquire power for themselves, even at the expense of others and the group as a whole. Without strong mechanisms for thwarting their ambitions, leadership will take on characteristics of dominance. Fortunately, strong mechanisms for preventing exploitation do exist in human societies, as we have seen, and they are applied with special force to leaders so that they do not abuse the power that they have been given. For instance, gossip and ridicule are focused primarily on important members of a group. Domineering leaders are resented compared to those who are generous, trustworthy, and empathetic. Of course, ambition and aggression in a leader might also be assets for the whole group, especially in competitive relationships with other groups, which might explain why many societies have separate leaders for war and peace (Van Vugt, 2006).

\section{Social Identity and Intergroup Relations}

Ingroup favoritism and outgroup hostility are the hallmarks of human social psychology, and MLS theory explains why. Between-group conflict has been a major force in human history, selecting for a range of group-level traits that may be costly for individuals but are hugely beneficial to their group. When particular conditions are met-such as the real or imagined presence of an outgroup-these traits become apparent. Minimal group experiments show that humans readily identify with and discriminate against members of outgroups even if they know that group membership is randomly decided by the flip of a coin (Brewer, 1979). Humans are also quite prepared to make substantial sacrifices by volunteering time, donating money, or taking risky actions to defend their group. MLS theory can provide a theoretical framework for these well-established results in social psychology and set an agenda for future research and practical applications (Kurzban \& Neuberg, 2005).

\section{Cultural Psychology}

The human major transition enabled our ancestors to spread over the globe-occupying hundreds of ecological niches-yet we remained a single biological species. It is amazing that a single species can acquire the adaptations to survive in environments as different as the frozen arctic, the arid desert, the humid rainforest, and remote islands thousands of miles from the mainland. This diversification requires a fast-paced process of cultural evolution (Richerson \& Boyd, 2005), with three major implications for psychological science.

First, cultural evolution requires a complex psychological infrastructure that evolved by genetic evolution. An analogy with the immune system is instructive. Our bodies are capable of rapidly adapting to diseases, but only thanks to a genetically evolved immune system that is mind-boggling in its complexity and sophistication when understood in detail. Something comparable must exist to explain our genetically innate capacity for 
rapid cultural adaptation, which should occupy center stage in psychological research.

Second, cultural evolution can create profound psychological differences among people, which are no less profound for being cultural rather than genetic. Social psychologist Richard Nisbett learned this over the course of his career, as he recounted at the end of a recent review article:

Almost two decades ago, the senior author wrote a book with Lee Ross entitled, modestly, Human Inference. Roy D'Andrade, a distinguished cognitive anthropologist, read the book and pronounced it a "good ethnography." The author was shocked and dismayed. But we now wholeheartedly agree with D'Andrade's contention about the limits of research conducted in a single culture. Psychologists who choose not to do cross-cultural psychology may have chosen to be ethnographers instead. (Nisbett, Peng, Choi, \& Norenzayan, 2001, p. 307)

Third, human activities such as music, dance, visual art, literature, and religion, which are associated more with the humanities than the human behavioral sciences, emerge as more worthy of scientific study when viewed from MLS perspective. These activities are culturally universal (although diverse in their specific expression), appear early in life, and-like sexdo not require incentives to perform because they are so pleasurable in their own right. In other words, they have all the earmarks of genetically evolved adaptations (Baumeister, 2005). Far from superfluous, they might play an essential role in defining groups, bonding their members together, coordinating their activities, and facilitating the social transmission of acquired information.

\section{INTEGRATING THE CONCEPT OF GROUPS AS ORGANISMS ACROSS ALL SCIENTIFIC DISCIPLINES}

It is an interesting fact, worth the attention of social historians, that the concept of the group as an organism was widely accepted until the middle of the 20th century, when it was rejected by various scientific disciplines. It is now making a comeback through the application of MLS thinking, providing a firm scientific foundation for the concept of groups as organisms- not as an axiomatic statement about all societies but as a possibility that is realized when certain conditions are met. This foundation can be built upon by psychology in addition to all other humanrelated disciplines, in an integration of knowledge that is the hallmark of evolutionary inquiry.

\section{Recommended Reading}

Richerson, P.J., \& Boyd, R. (2005). (See References). A comprehensive account of human cultural evolution from a multilevel evolutionary perspective.

Wilson, D.S. \& Wilson, E.O. (2007). (See References). A recent assessment of multilevel selection theory for a broad academic audience.
Wilson, D.S. (2007). Evolution for everyone: How Darwin's theory can change the way we think about our lives. New York: Delacorte Press. The first account of evolution and its implications for human affairs for a general audience that is based on multilevel selection theory.

\section{REFERENCES}

Baumeister, R.F. (2005). The cultural animal: Human nature, meaning, and social life. New York: Oxford University Press.

Boehm, C. (1999). Hierarchy in the forest. Cambridge, MA: Harvard University Press.

Brewer, M.B. (1979). Ingroup bias in the minimal group situation: A cognitive-motivational analysis. Psychological Bulletin, 86, 307324 .

Campbell, D.T. (1994). How individual and face-to-face group selection undermine firm selection in organizational evolution. In J.A.C. Baum \& J.V. Singh (Eds.), Evolutionary dynamics of organizations (pp. 23-38). New York: Oxford University Press.

De Cremer, D., \& Van Vugt, M. (1999). Social identification effects in social dilemmas: A transformation of motives. European Journal of Social Psychology, 29, 871-893.

Fehr, E., \& Gäechter, S. (2002). Altruistic punishment in humans. Nature, 415, 137-140.

Haidt, J. (2007). The new synthesis in moral psychology. Science, 316, 998-1002.

Kurzban, R., \& Neuberg, S. (2005). Managing ingroup and outgroup relationships. In D.M. Buss, (Ed.). Handbook of Evolutionary Psychology (pp. 653-675). Hoboken, NJ: Wiley.

Maynard Smith, J., \& Szathmary, E. (1995). The major transitions of life. New York: W.H. Freeman.

Mullen, B., Johnson, C., \& Salas, E. (1991). Productivity loss in brainstorming groups: A meta-analytic integration. Basic and Applied Social Psychology, 12, 3-24.

Nisbett, R.E., Peng, K., Choi, I., \& Norenzayan, A. (2001). Culture and systems of thought: Holistic vs. analytic cognition. Psychological Review, 108, 291-310.

Richards, R.J. (1987). Darwin and the emergence of evolutionary theories of mind and behavior. Chicago: University of Chicago Press.

Richerson, P.J., \& Boyd, R. (2005). Not by genes alone: How culture transformed human evolution. Chicago: University of Chicago Press.

Seeley, T. (1995). The wisdom of the hive. Cambridge, MA.: Harvard University Press.

Sober, E., \& Wilson, D.S. (1998). Unto others: The evolution and psychology of unselfish behavior. Cambridge, MA: Harvard University Press.

Van Vugt, M. (2006). Evolutionary origins of leadership and followership. Personality and Social Psychology Review, 10, 354-371.

Wegner, D.M. (1986). Transactive memory: A contemporary analysis of the group mind. In B. Mullen \& G. Goethals (Eds.), Theories of group behavior (pp. 185-208). New York: Springer-Verlag.

Williams, G.C. (1966). Adaptation and natural selection. Princeton: Princeton University Press.

Wilson, D.S., Timmel, J., \& Miller, R.R. (2004). Cognitive cooperation: when the going gets tough, think as a group. Human Nature, 15, $225-250$.

Wilson, D.S., \& Wilson, E.O. (2007). Rethinking the theoretical foundation of sociobiology. Quarterly Review of Biology, 82, 327-348. 


\section{Author Query Form}

\section{Journal CDIR}

Article $\quad 538$

Dear Author,

During the copy-editing of your paper, the following queries arose. Please respond to these by marking up your proofs with the necessary changes/additions. Please write your answers clearly on the query sheet if there is insufficient space on the page proofs. If returning the proof by fax do not write too close to the paper's edge. Please remember that illegible mark-ups may delay publication.

\begin{tabular}{|c|l|l|}
\hline Query No. & \multicolumn{1}{|c|}{ Description } & Author Response \\
\hline & No Queries & \\
\hline & & \\
\hline & & \\
\hline & & \\
\hline & & \\
\hline & & \\
\hline & & \\
\hline & & \\
\hline & & \\
\hline
\end{tabular}

